\title{
UM TEXTO CRÍTICO DE MACHADO DE ASSIS
}

\section{APRESENTAÇÃO E NOTAS DE}

JOSÉ AMÉRICO MIRANDA

Universidade Federal do Espírito Santo / Universidade Federal de Minas Gerais Vitória, Espírito Santo, Brasil / Belo Horizonte, Minas Gerais, Brasil

\section{ALEX SANDER LUIZ CAMPOS}

Instituto Federal do Norte de Minas Gerais / Universidade Federal de Minas Gerais Almenara, Minas Gerais, Brasil / Belo Horizonte, Minas Gerais, Brasil

\section{A Bibliografia de Machado de Assis, publicada por José Galante de Sousa em 1955, registra, para o ano de 1898, as seguintes publicações - Lo autor: 1. "Relógio parado", conto, em A Estação; 2. "O velho} Senado", na Revista Brasileira; 3. "Procelárias, por Magalhães de Azeredo", crítica, também na Revista Brasileira. ${ }^{1}$ Em obra posterior, Machado de Assis e outros estudos, em que acrescenta pelo menos uma descoberta importante à bibliografia do autor - o primeiro poema publicado por ele, que não constava da Bibliografia -, nada acrescenta aos dados relativos ao ano de $1898 .^{2}$

Raimundo Magalhães Júnior, outro grande pesquisador, que localizou diversos textos não resgistrados na Bibliografia de Galante de Sousa, afirma o seguinte, sobre aquele ano: "Em 1898, Machado publicara apenas três trabalhos $^{\prime 3}$ - e enumera, na sequência, os mesmos trabalhos registrados por Galante em sua Bibliografia.

Machado de Assis, no entanto, foi muito claro, em carta dirigida a Magalhães de Azeredo, datada do Rio de Janeiro, 25 de dezembro de 1898:

Há de saber que desde 17 de novembro estou de Secretário do Ministro da Viação. O que não sabe talvez é que o meu trabalho é agora imenso, e dizendo-lhe eu que saio todos os dias da Secretaria ao anoitecer, e, não obstante, trabalho em casa, logo cedo, e aos domingos também, poderá imaginar a vida que levo. Daí a longa demora desta resposta, à última

${ }^{1}$ Cf. SOUSA, Bibliografia de Machado de Assis, p. 675-676.

${ }^{2}$ Cf. SOUSA, Machado de Assis e outros estudos.

${ }^{3}$ MAGALHÃES JÚNIOR, Vida e obra de Machado de Assis, vol. 4, p. 89. 
carta sua. Não vá agora pagar-me na mesma moeda. Sabe o gosto que me dão as suas letras, tão amigas, tão sisudas, tão cheias de arte e mocidade. Não diga (se já leu os meus dois artigos sobre as Procelárias) não diga que sempre me sobrou algum tempo para eles. O da Revista Brasileira, aliás simples nota bibliográfica, foi escrito antes da minha nomeação, e o segundo, dado no Jornal do Comércio, não saiu como eu quisera, porque já foi escrito depois de 17 de novembro; não lhe pude dar maior desenvolvimento. Não obstante, disse em ambos os lugares o que penso e sinto daquele livro de versos, e aqui lhe repito com a mesma cordialidade. Nem eu esperava menos já porque conhecia grande parte dele, já porque o seu talento é dos que sempre me deram mais esperanças - e mais sérias. ${ }^{4}$

É curioso que, sendo tão inequívoco o autor, a peça de crítica literária publicada no Jornal do Commercio tenha continuado ausente de sua Bibliografia, das diversas coletâneas de textos seus dispersos, das coletâneas de suas críticas literárias, que já receberam inúmeras edições, e das obras completas, que, aos poucos, aumentaram de volume, pelo acréscimo de textos encontrados. ${ }^{5}$ Em seu Dicionário de Machado de Assis, obra cuidadosa e exaustiva, que atualiza o repertório dos textos conhecidos de Machado de Assis e retifica informações constantes na Bibliografia elaborada por Galante, Ubiratan Machado não menciona a crítica às Procelárias publicada no Jornal do Commercio, registrando apenas o texto divulgado, no mesmo ano, na Revista Brasileira. No verbete dedicado ao Jornal do Commercio, esse estudioso afirma que Machado, no decurso de sua trajetória como escritor e jornalista, colaborou apenas oito vezes no periódico fundado por Pierre Plancher. Ubiratan Machado elenca esses textos, poucos, mas que cobrem praticamente toda a carreira de Machado de Assis: vão de 1858, com o poema "Mont'Alverne", até 1904, com o artigo "A Paixão de Jesus". 6 O texto crítico mencionado por Machado na carta a Magalhães de Azeredo eleva para nove o número de textos seus publicados nesse periódico.

Pois é tal a peça com que nos deparamos recentemente nas páginas do Jornal do Commercio de 18 de dezembro de 1898, subscrita com a assinatura "Machado de Assis". Até onde foi possível verificar, esse texto permaneceu esquecido pelos estudiosos do autor por quase 120 anos. Muito provavelmente, sua divulgação no presente número de Machado de Assis em

\footnotetext{
${ }^{4}$ ASSIS, Correspondência de Machado de Assis: tomo III, 1890-1900, p. 339-340.

${ }^{5}$ Cf., por exemplo: ASSIS, Dispersos de Machado de Assis; ASSIS, Machado de Assis: crítica literária e textos diversos; ASSIS, Textos inéditos em livro; ASSIS, Obra completa em quatro volumes, vol. 3.

${ }^{6}$ MACHADO, Dicionário de Machado de Assis, p. 277 e 176-177.
} 


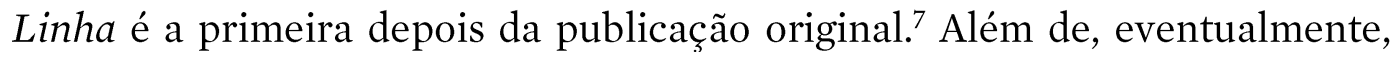
vir a fornecer elementos para uma melhor compreensão da atividade de Machado como crítico, a peça ora publicada também chama a atenção para a colaboração desse escritor no Jornal do Commercio, uma colaboração bastante irregular, e num jornal tido como pouco interessado em assuntos literários. Talvez em razão disso o olhar e a atenção dos pesquisadores não se tenham fixado nesse periódico, nem por ele tenham demonstrado a mesma atenção que dispensaram a outras folhas nas quais colaborou Machado de Assis.

Na edição da crítica às Procelárias, utilizou-se como fonte o fac-símile disponível na Hemeroteca Digital da Fundação Biblioteca Nacional. ${ }^{8}$ A ortografia foi atualizada conforme o Acordo Ortográfico de 1990, em vigor no Brasil desde 2009. Mantiveram-se as formas "dous" e "cousa". Padronizaramse as citações feitas no texto de acordo com as normas desta revista (no jornal, em razão do pequeno espaço disponível na coluna, alguns versos isolados não apresentavam o recuo). As citações de versos (quer de poetas estrangeiros, quer da obra de Magalhães de Azeredo) foram transcritas em acordo com edições confiáveis, preparadas por especialistas ou pelo próprio autor, no caso de Azeredo; em rodapé registrou-se a lição presente no Jornal do Commercio. Foram elaboradas algumas notas ao texto, todas de nossa responsabilidade; informações presentes nessas notas, cujas fontes não estão nelas indicadas, foram obtidas em obras de consulta que constam das referências ao final do texto.

\footnotetext{
${ }^{7}$ Já estava este nosso texto em preparo para publicação, quando nos deparamos com a referência de um artigo com o mesmo título do nosso, de autoria de Antônio Houaiss, publicado em 14 de agosto de 1959 no Jornal do Commercio. Não sabemos a que texto crítico de Machado de Assis se refere Houaiss. (Cf. MACHADO, Ubiratan. Bibliografia machadiana 1959-2003. São Paulo: Ed. da USP, 2005. p. 20). ${ }^{8}$ Cf. $<$ http://memoria.bn.br/DocReader/docreader.aspx?bib=364568_08\&PagFis=30652>.
} 


\section{LITERATURA $^{9}$}

\section{MAGALHÃES DE AZEREDO. Procelárias. Porto: Empresa Literária e Tipográfica, $1898 .^{10}$}

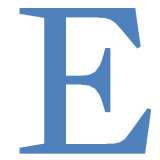

ste primeiro livro de Magalhães de Azeredo, apesar de ser uma coleção de versos esparsos, impressos aqui e ali, alguns deles inéditos, muitos datados de 1890 e 1891, podemos dizer que é o livro das suas estreias literárias. O mesmo direi do homem, que não entra agora na diplomacia, mas propriamente estreia a carreira diplomática, encarregado de negócios junto da Santa Sé, à espera de um Ministro. Se o Ministro não fosse, e a carreira consentisse, bem podia lá ficar com este outro título. Mas falemos só dos versos.

Um claro espírito do princípio deste século, Fontanes, ${ }^{11}$ cuidava de coligir os seus, quando o primeiro Cônsul o convidou à carreira pública; dizem que suspendeu logo a impressão. Não sei se perdeu ou ganhou com isso. Magalhães de Azeredo é que perderia, decerto, se em respeito ao cargo, destruísse este seu volume das Procelárias. Quaisquer que sejam as outras aptidões do autor, a arte é a sua vocação principal. A capacidade de espírito é nele suficiente para acudir às musas e ao protocolo. De resto, serve ao Brasil junto a um papa, que, apesar dos anos, dos achaques, e dos graves cuidados do seu ministério, não pendurou ainda a lira latina, e anuncia para a mesma data uma encíclica e um poema. ${ }^{12}$ A terra é própria a esta espécie de acumulação.

Já o título destas Procelárias é feliz e define com acerto a poesia, o espírito e a vida do autor. Quanto à vida as boas fadas o receberam neste mundo. Um de seus distintos companheiros de S. Paulo, Mário de Alencar, publicou ultimamente na Revista Moderna um perfil literário de Magalhães de Azeredo, onde vemos que também elas o acolheram à porta da academia. ${ }^{13}$ Em toda parte foi sempre amado. Qualquer que seja o tumulto exterior, Magalhães de Azeredo viveu como as suas aves, que a despeito das procelas,

\footnotetext{
${ }^{9}$ Jornal do Commercio, Rio de Janeiro, ano 78, n. 351, p. 1. Domingo, 18 de dezembro de 1898.

${ }^{10}$ No Jornal do Commercio (JC), "Procellarias - Porto, Empreza Litteraria e Typographica. 1898".

${ }^{11}$ Louis-Marcelin, marquês de Fontanes (1757-1821), poeta e político francês. Suas obras foram editadas por Sainte-Beuve em 1837.

12 Referência ao papa Leão XIII (1810-1903), que foi poeta latino e autor de numerosas encíclicas, a mais famosa das quais a Rerum novarum, de 1891, em que forneceu bases para o pensamento social da Igreja. Ficou conhecido como papa das encíclicas sociais.

${ }^{13}$ De fato, o artigo de Mário de Alencar, com cinco fotografias do poeta de Procelárias, saiu na edição de julho de 1898 da Revista Moderna. Cf. ALENCAR, Magalhães de Azeredo.
} 
correm no espaço brandas e serenas. Não importa o embruscado do ar; os seus versos sobem, descem, circulam, com as asas apenas molhadas e as plumas inteiras. Se alguma vez o poeta parece descrer ou desanimar, não chega a maldizer de nada ou por muito tempo; é antes obra da sensibilidade do autor que propriamente a realidade da ação da vida.

Versos esparsos, quando se coligem, precisam de resistir a esta segunda forma de publicidade; alguns a pedem de si mesmos. O Sr. Magalhães de Azeredo agrupou e completou os seus com método, definindo na primeira página o título que lhes deu. ${ }^{14}$ Um título não é muito. Alguns há sem livros, como dizia Garrett, a propósito daquele Poeta em anos de prosa que Manuel de Figueiredo pôs a uma das suas comédias. ${ }^{15}$ Se o nosso jovem compatrício o levantar dali algum dia para um livro, fará sempre obra de poeta, a despeito dos anos de prosa, tão essencial é nele o amor puro da arte. Sem desmentir os grandes sentimentos das duas páginas votivas das Procelárias, cantados com a doçura e a gravidade que caracterizam seu estilo, é certo que o artista completa nele o filho e o esposo. ${ }^{16}$

Antes de tudo subjetivo, é também artista delicado e sutil, que sabe fazer e perfazer as suas estrofes. A língua é boa, como a rima, e porque busca falar quando tem que dizer, os versos saem-lhe com alguma cousa mais que si mesmos. Cada um é poeta do seu temperamento, antes de ${ }^{17}$ o ser de uma escola, mas aqui não achareis nenhuma escola exclusiva. O autor das Procelárias tem as novas lições da forma, um fino lavor moderno; contudo, aquele que convidava a compor versos antigos com ideias novas,

Sur des pensers nouveaux faisons des vers antiques,

seria entendido por Magalhães de Azeredo, que tira ao novo o que é novo, deixando o que é apenas moda, e acha em si maneira de não ser reflexo nem

\footnotetext{
14 "Procelárias" é o título do poema que abre o livro.

${ }^{15}$ Referência ao capítulo IX de Viagens na minha terra, em que Garrett faz referência à comédia, que tem esse título, do poeta árcade Manuel de Figueiredo (1725-1801; nome árcade: Lícidas Cíntio). Cf. BRAGA, História da literatura portuguesa, vol. 4. Diz Garrett, em Viagens na minha terra: "Poeta em Anos de Prosa! Oh! Figueiredo, Figueiredo, que grande homem não foste tu, pois imaginaste esse título, que só ele em si é um volume! Há livros, e conheço muitos, que não deviam ter títulos, nem o título é nada neles. [...] / E há títulos também que não deviam ter livro, porque nenhum livro é possível escrever que os desempenhe como eles merecem. / Poeta em Anos de Prosa [é] um desses". (GARRETT, Obras de Almeida Garrett, vol. I, p. 45).

16 A primeira parte do livro, que se segue ao poema "Procelárias", intitulada "Votivas", traz dois poemas: "A minha mãe" e "À escolhida".

${ }^{17}$ No $J C$, "do".
} 
eco. ${ }^{18}$ É um moderno que está na legião, sem se perder nela. Quando se houver de narrar a batalha ele será contado entre os que, pelo ardor generoso e pessoal, se distinguem na confusão dos golpes e marcham melhor sem sair da linha e do compasso.

E pois que falamos de legião e de combate, lede o "Escudo", uma das páginas do livro. Aí vereis o sentimento que Magalhães de Azeredo tem da arte. O quadro representa um velho mirando pela última vez o escudo que levou às cruzadas, mandou pendurar e nunca mais serviu a ninguém. Não quis morrer sem contemplá-lo. ${ }^{19}$ De onde saiu a lenda que põe o escudo por impossível de sobraçar, e mais de um que tentou fazê-lo, caiu ao peso dele. Tal é a arte. Dizendo-lhe que

Cumpre ter força e fé, como um herói antigo, Para te merecer e para conquistar-te! ${ }^{20}$

o poeta alude aos muitos que tentaram sair a combate com aquela arma da lenda, e não lograram levantá-la, e fala de si com esta delicadeza de sentimento poético:

Mas, quando eu mesmo caia, ignorado do vulgo,

Sob o meu próprio esforço inútil sucumbindo,

Morrerei orgulhoso em teu prol, e, caindo,

Direi: Como te adoro, e que feliz me julgo!

Assim, se na "Última página" contenta-se de haver merecido a vida, nesta basta-lhe ao seu amor da arte o esforço de a haver buscado. ${ }^{21}$ Quer dizer que a mesma produção traz em si um gosto primeiro e único, independente dos seus últimos fins.

Citei a "Última página". É a que exprime a reação do poeta contra a rudez da vida e a troca da fortuna. São as derradeiras palavras da Musa, que o convida a encarar o mal e vencê-lo. Então, embora suspire que os seus versos

\footnotetext{
${ }^{18}$ Referência ao poeta francês André Chénier (1762-1794). O verso citado - "De novos pensamentos façamos versos antigos" - se encontra no poema "L’invention". Cf. CHÉNIER, CEuvres complètes, p. 127. A lembrança do poeta francês não é fortuita; o livro de Magalhães de Azeredo tem por epígrafe um verso seu - "L'art ne fait que des vers, le cœur seul est poète" ("A arte não produz senão versos, só o coração é poeta"). Traduções nossas.

${ }^{19}$ No $J C$, "contempla-lo-".

${ }^{20}$ No $J C$, "conquistar-te".

21 "Última página" é o título da última seção do livro, composta por apenas um poema, "A Musa ao Poeta".
} 
podem morrer, e confesse que o zelo haverá sido inútil, uma cousa o consola, contemplando as estrelas, é que nelas se embebeu a luz que nele havia. Werther, na última noite, ao mirá-las no "céu eterno", tinha a mesma consolação: "Não, vós não caireis... Deus vos traz em si, como a mim!". A diferença da esperança entre o namorado de Carlota e o poeta das Procelárias é a Musa que a exprime quando lhe diz no fim do livro:

medindo num relance

A estrada feita desde o ponto de partida,

Tu poderás dizer que mereceste a Vida!

Um não merecia a vida, tanto que a despiu. Outro, não somente a merece, como achará nela o prêmio de seus trabalhos. Não a viveu toda neste livro, embora o diga no verso final da composição, que ainda uma vez reli com íntimo afeto: "No limiar". ${ }^{22} \mathrm{O}$ tempo lhe irá virando as folhas, e o poeta achará nelas margem sobeja para as suas iluminuras. As sensações deste primeiro tomo são geralmente brandas, o entusiasmo não tem vertigens, nem o desespero convulsões. O amargor decompõe-se logo na doçura, a tristeza faz-se alegria, o ridente passa a melancólico, para tornar sem demora à primeira alma. Em tudo, porém, este moço grave não perde a compostura. Aquele outro das Cantigas de Espanha e da Itália disse que os seus versos de estreia eram de criança e só aos últimos atribuía um pouco de homem. ${ }^{23}$ Já aqui há um homem, um princípio de homem, se quiserdes, um que adivinha o que não padeceu, e alguma vez descobre pela imaginação o mal do mundo. Mas é virtualmente um otimista.

Há aqui duas evocações que dão bem a fisionomia deste lírico: Lamartine e Anacreonte. Por mais que os nomes se desmintam, é certo exprimirem as simpatias do nosso poeta. No primeiro sedu-lo a ternura e a castidade, no segundo a juventude teimosa e perpétua; jovem ancião, como ele lhe chama:

Jovem ancião, coroado de boninas,

\footnotetext{
22 O "íntimo afeto" do crítico se explica: o poema "No limiar" não só lhe é dedicado, mas lhe é dirigido. Seu último verso é este: "Porque este livro, Mestre, é a vida que eu vivi!". O "Mestre", do verso, é Machado de Assis (AZEREDO, Procellarias, p. 20).

${ }^{23}$ Referência a Alfred de Musset e a seus Contes d'Espagne et d'Italie. As Poésies complètes do autor, publicadas em 1840, traziam o soneto "Au lecteur", cujo terceto final é este: "Mes premiers vers son d'un enfant,/ Les seconds d'un adolescent,/ Les derniers à peine d'un homme". Cf. DORÉ, Avertissement bibliographique et critique pour les deux volumes de poésies, p. X; MUSSET, Premières poésies 18281833 , p. 2.
} 
Cãs úmidas de nardo recendente,

Nunca farto de gozo, ou descontente, ${ }^{24}$

Entre mancebos e mulheres finas,

Sem um leve tremor nas mãos divinas, Arrancavas da lira obediente

Cânticos imortais, que inda no Oriente

Repete a brisa às fontes cristalinas.

Tu sábio! tu feliz! em luta rude

De ambições vãs e de írritos desejos,

Não consumiste ${ }^{25}$ a eterna juventude!

Foram doces teus dias, ${ }^{26}$ como adejos

De pombas, como notas de alaúde,

Como sussurros plácidos de beijos...

Quisera transcrever muitos versos destes, "Oblivion", por exemplo, que é das mais finas páginas do livro, como o "Soneto negro" ou "Em desalento", para citar somente esses dous sonetos capitais. O "Soneto negro" dá-nos ainda uma nota íntima; o mesmo homem que sentirá um dia o gosto de haver cantado, ainda sem deixar memória de si, como no "Escudo", aqui padece com a ideia de cair morto e com ele os seus cantos. As datas explicarão o contraste, posto que a segunda das composições não traga nenhuma; mas, a mesma que fosse, não faria desdizer um sentimento de outro. Ao contrário, as duas resolvem-se na única adoração da poesia.

"Ode triunfal", "Estatuária de Amor", "Velhice de D. Juan", pertencem ao número das que sobressaem pelo conceito, pela forma, pela originalidade. $\mathrm{O}$ sentimento tem grande parte nas duas primeiras, às quais o autor deu ainda a variedade do metro, e, com isto, maior movimento. A última é composta em terza rima, mais adequada que nenhuma outra às últimas noites do grande pecador. ${ }^{27} \mathrm{D}$. Juan está velho e acabado, encosta-se à janela

\footnotetext{
${ }^{24}$ No $J C$, "desconteete,".

25 No $J C$, "consumistes".

${ }^{26}$ Sem vírgula no $J C$.

${ }^{27} \mathrm{Na}$ verdade, o poema de Azeredo está composto em tercetos, com versos alexandrinos e esquema de rimas aba/cbc, alterando-se a rima "b" a cada par de tercetos - o que obriga o poema a ter número par de tercetos. Na terza rima, o verso em geral é o decassílabo, e o esquema de rimas é aba/bcb/cdc/ded etc., sendo que ao último terceto segue-se mais um verso, incorporado ou não ao corpo da última estrofe, que fecha o esquema das rimas. No padrão do poema "Velhice de Don Juan" (p. 115-123), mas em versos octossílabos, está composto o poema "Procelárias" (p. 3-6); e, no padrão da terza rima, estão
} 
e mira o céu. Aparece a primeira estrela. Ele, a quem só falta a "emoção da morte" pensa nas muitas mulheres que possuiu. Estas não lhe surdem como as outras pecadoras de Dante:

Di qua, di là, di giù, di sù li mena, ${ }^{28}$

ele é que as evoca de memória, não por saudade ou piedade, mas por uma espécie de ódio senil, que afinal cansa também, e a voz lhe morre, depois de maldizer todas. Em todas achou dolo. Mas, já então a noite caminhara, e a estrela, que era uma no princípio da noite, são agora infinitas e todas resplandecem como...

- Como olhos de Mulher abertos sobre o mundo...29

Assim respondem as vítimas do sedutor defunto, mostrando que a vida continua a vida, ${ }^{30}$ e que ao amor não importam enfastiados. Creio ser tal a ideia do poeta. Essa página é de $1893 .^{31}$

Também se pode dizer que neste livro não importam ao nosso autor as grandes ações do mundo. Entretanto, não há muitos meses deu-nos a ode "A Portugal", ${ }^{32}$ por ocasião do centenário das Índias, que é das mais belas composições suas, e devia estar aqui. ${ }^{33}$ Também ela, e mais que as outras, é procelária. Os versos vão mar fora, como os navegantes daquela idade, rompendo as águas e os céus, fortes e seguros. Magalhães de Azeredo preferiu talvez o opúsculo para fazer acompanhar os versos da carta a Eça de

compostos os poemas "Serenata" (p. 58-62), mas em versos de sete sílabas, e "Trenos" (p. 93-99) e "Dante" (p. 193-202), estes em versos de dez sílabas. Machado de Assis, por sua vez, empregou a terza rima em "No limiar", de Crisálidas; na tradução do salmo 136, incluído na seção IX da Parte Primeira de "A cristã-nova", de Americanas; na "Última jornada", de Americanas; e em "Dante (Inferno, canto $\mathrm{XXV)",} \mathrm{de} \mathrm{Ocidentais.}$

${ }^{28}$ No JC, "Di quá, di lá, di giú, di su’ gli mena;". Verso da Divina comédia, de Dante (canto V do Inferno): "Daqui, dali, abaixo, acima as move" (tradução nossa).

${ }^{29}$ No $J C$, "Como olhos de Mulher abertos sobre o mundo", sem travessão e sem reticências.

30 Talvez a repetição de "a vida" nessa passagem seja indevida. No $J C$, há pequena mancha tipográfica antes da segunda ocorrência da expressão.

${ }^{31}$ Em Procelárias, o poema "Velhice de Don Juan" vem datado de 1894.

32 No JC, "ode a Portugal,".

33 A ode "A Portugal", de Magalhães de Azeredo, foi transcrita no tomo XIV da Revista Brasileira, onde trazia a seguinte Nota da Redação: "Ao rei de Portugal ofereceu a Comissão Romana das festas do Centenário da Índia um álbum, em cuja primeira página vem uma poesia do papa Leão XIII. Foi para esse álbum e a convite daquela comissão que o nosso colaborador Sr. Magalhães de Azeredo escreveu estes versos, que graças a uma delicada atenção sua a Revista tem o prazer de publicar. N. da R." (AZEREDO, A Portugal, no centenário da descoberta das Índias, p. 231, ortografia atualizada). 
Queirós, mostrando assim, lado a lado, o poeta e o prosador, e tanto como eles, o pensador. ${ }^{34}$ Creio que as composições de prosa, estudos, viagens, narrativas, outros escritos, alguns já conhecidos, virão em livro a seu tempo. Magalhães de Azeredo é das nossas vocações literárias mais brilhantes. Tem a paixão do trabalho, a paciência do estudo, o gosto da perfeição. Somai isto com o talento e esperai.

\section{MACHADO DE ASSIS}

FONTE: Jornal do Commercio / D. A. Press

\section{Referências}

ALENCAR, Mário de. Magalhães de Azeredo. Revista Moderna, Paris, n. 23, p. 725729, jul. 1898. Disponível em:

<http://memoria.bn.br/DocReader/docreader.aspx?bib=282383\&PagFis=923>.

Acesso em: 22 jun. 2016.

ALIGHIERI, Dante. Commedia. Disponível em:

$<$ http://www.danteonline.it/italiano/opere.asp?idope=1\&idlang=OR $>$.

Acesso em: 29 jun. 2016.

ASSIS, Machado de. Correspondência de Machado de Assis: tomo III, 1890-1900.

Coord. e orientação de Sergio Paulo Rouanet; reunida, org. e comentada por Irene Moutinho e Sílvia Eleutério. Rio de Janeiro: ABL, 2011 (Coleção Afrânio Peixoto, v. 98). Disponível em:

$<$ http://www.academia.org.br/sites/default/files/publicacoes/arquivos/cap-098corresp_de_ma_-tomo_iii_-_1890-1900_-_para_internet.pdf $>$.

Acesso em: 16 maio 2016.

. Dispersos de Machado de Assis. Coligidos e anotados por Jean-Michel Massa.

Rio de Janeiro: Instituto Nacional do Livro, 1965. . Machado de Assis: crítica literária e textos diversos. Org. de Sílvia Maria Azevedo, Adriana Dusilek e Daniela Mantarro Callipo. São Paulo: Ed. Unesp, 2013.

Magalhães de Azeredo. Procellarias - Porto, Empreza Litteraria e Typographica. 1898. Jornal do Commercio, Rio de Janeiro, n. 351, p. 1, 18 dez. 1898. Seção "Litteratura". Disponível em:

\footnotetext{
34 Magalhães de Azeredo publicara, meses antes de Procelárias, uma plaqueta de 31 páginas com a ode "A Portugal" antecedida de uma carta a Eça de Queirós. Cf. AZEREDO. A Portugal no centenario das Indias.
} 
$<$ http://memoria.bn.br/DocReader/docreader.aspx?bib=364568_08\&PagFis=30652>. Acesso em: 21 jun. 2016.

Obra completa em quatro volumes. Org. de Aluizio Leite, Ana Lima Cecilio e Heloisa Jahn. 3. ed. São Paulo: Nova Aguilar, 2015, 4 vols. (Biblioteca LusoBrasileira. Série Brasileira).

Textos inéditos em livro. Org. de Mauro Rosso. Rio de Janeiro: Academia Brasileira de Letras, 2014. (Coleção Afrânio Peixoto, vol. 102).

AZEREDO, Magalhães de. A Portugal no centenario da descoberta das Indias. Revista Brasileira, Rio de Janeiro, tomo XIV, p. 231-237, abr.-jun. 1898. Disponível em:

<http://memoria.bn.br/DocReader/DocReader.aspx?bib=139955\&PagFis=12220>. Acesso em: 22 jun. 2016.

A Portugal no centenario das Indias (Com uma carta ao Sr. Eça de Queiroz). Genova: Tipografia R. Istituto Sordo-Muti, 1898.

Procellarias. Porto: Typographia a vapor da Empreza Litteraria e Typographica, 1898.

BRAGA, Teófilo. História da literatura portuguesa. [Lisboa]: Imprensa Nacional Casa da Moeda, 1984, vol. 4, Os Árcades.

CHÉNIER, André. Euvres complètes. Texte établi et commenté par Gérard Walter. Paris: Gallimard, 1966 (Bibliothèque de la Pléiade, vol. 57).

DORÉ, R. Avertissement bibliographique et critique pour les deux volumes de poésies. In: MUSSET, Alfred de. Premières poésies 1828-1833. Paris: Louis Conard, 1922, p. IX-XV.

ENCYCLOPEDIA e diccionario internacional. Lisboa: W. M. Jackson, [19--], 20 vols. GARRETT, Almeida. Obras de Almeida Garrett. Porto: Lello \&Irmão, 1963, vol. I. GRANDE ENCICLOPÉDIA Larousse cultural. São Paulo: Universo, 1988. 8 v.

MAGALHÃES JÚNIOR, R. Vida e obra de Machado de Assis. Rio de Janeiro: Civilização Brasileira, 1981, 4 vols.

MUSSET, Alfred de. Premières poésies 1828-1833. Paris: Louis Conard, 1922. (CEuvres complètes de Alfred de Musset).

SOUSA, J. Galante de. Bibliografia de Machado de Assis. Rio de Janeiro: Instituto Nacional do Livro, 1955 (Coleção B I - Bibliografia, vol. 10).

1979. 
ALEX SANDER LUIZ CAMPOS é graduado em Letras pela Universidade Estadual de Montes Claros (Unimontes), mestre e doutorando em Estudos Literários pela Universidade Federal de Minas Gerais (UFMG) e professor no Instituto Federal do Norte de Minas Gerais (IFNMG). E-mail: alexslcampos@gmail.com.

JOSÉ AMÉRICO MIRANDA é professor de Literatura Brasileira da Faculdade de Letras da Universidade Federal de Minas Gerais (UFMG), aposentado. Atualmente, pesquisador DCR (Desenvolvimento Científico Regional/CNPq) junto ao Programa de Pós-Graduação em Letras da Universidade Federal do Espírito Santo (UFES), com apoio da Fundação de Amparo à Pesquisa e Inovação do Espírito Santo (FAPES). E-mail: bmaj@uol.com.br.

Recebido: 01.07.16

Aprovado: 12.07 .16 